\title{
Genetic diversity analysis in tossa jute (Corchorus olitorius L.) germplasm lines
}

\author{
Jawahar Lal Jatothu' ${ }^{1}$, A. Anil Kumar ${ }^{2 *}$, S. B. Choudhary ${ }^{2}$, H. K. Sharma ${ }^{2}$, R. T. Maruthi, \\ C. S. Kar' ${ }^{2}$ and J. Mitra ${ }^{2}$ \\ ${ }^{1}$ Crop Improvement Division, ICAR-Indian Institute of Oil seeds Research, Hyderabad (Telangana), INDIA \\ ${ }^{2}$ Crop Improvement Division, ICAR-Central Research Institute for Jute and Allied Fibres, Barrackpore \\ (West Bengal), INDIA \\ *Corresponding author. E-mail: anil.arroju@gmail.com \\ Received: June 13, 2015; Revised received: December 7, 2017; Accepted: January 2, 2018
}

\begin{abstract}
An experiment was conducted to examine the magnitude of genetic diversity and characters contributing to genetic diversity among 81 tossa jute genotypes. Cluster analysis based on Euclidean squared distances and ward's method, the genotypes were grouped into ten distinct clusters. Analysis reveals that stick weight contributes maximum to the phenotypic diversity $(65.52 \%)$ followed by green weight (13.64\%) and fibre yield (10.10\%). Among the clusters Cluster IX recorded highest mean fibre yield $(19.91 \mathrm{~g})$ followed by Cluster VII $(18.94 \mathrm{~g})$ and these clusters also recorded high mean values for plant height, basal diameter, green weight and stick weight. The highest intercluster distance was 186.80 (between clusters II and X) followed by 161.26 (between clusters IV and X), indicating the wide genetic diversity among these clusters. The highest intra-cluster distance was observed in cluster II (20.34) and the lowest in cluster $X$ (3.17). The average inter-cluster distances were higher than the average intra-cluster distances, which shows the presence of wide genetic diversity among the genotypes of different clusters than those of the same cluster. The first two principal components, whose Eigen values are greater than one, accounted for $74 \%$ of the total variation among the five characters. The information obtained from diversity analysis is useful in planning further breeding programme for tossa jute improvement.
\end{abstract}

Keywords: Cluster analysis, Genetic diversity, Principal component analysis, Tossa jute

\section{INTRODUCTION}

The genus Corchorus belongs to family Malvaceae and comprises of 50-60 species (Mahapatra and Saha, 2008) naturalized mostly as annual herbs in tropical and sub-tropical regions of Africa, America, Australia and Asia (Edmonds, 1990). The biodegradable lignocellulosic fibre extracted through microbial decomposition of whole plants of Corchorus species is commonly known as jute. In India nine species of the genus are reported (Sinha et al., 2011), of which only two are commercially cultivated viz., C. olitorius (tossa jute) and C. capsularis (white jute). Jute is the second most important natural fibre crop after cotton (Rowell and Stout, 2007). Jute has a great potential in manufacturing diversified value-added industrial products and packaging materials like sacks, hessian, burlaps, rope, geotextiles, and fibre composites.

Among the two cultivated species, tossa jute cultivars were intrinsically high yielders hence it occupied about $90 \%$ of jute growing area in the country. India produces raw jute fibre of 11.49 million bales from 0.80 million ha of area with an average productivity of $25.77 \mathrm{q} /$ ha in 2014-15 (www.jutecomm.gov.in). During 2014-
15 India exported raw jute of $88.6 \mathrm{M}$. tonnes worth 1006 crores, with the growing demand from the western countries for this biodegradable fibre, there is an urgent need to increase the yield levels. The yield levels of the cultivated varieties have plateaued as the most of the released varieties were developed from few selected parents (Kar et al., 2009; Benor et al., 2012; Kundu et al., 2013).

The success of any breeding programme in developing high yielding varieties depends on the knowledge of nature and magnitude of genotypic and phenotypic variability present in the crop species (Abdurakhmonov and Abdukarimov, 2008). Diversity analysis is an efficient tool in quantifying the magnitude of genetic variability present in the study material. Diversity study helps in identification of genetically diverse germplasm lines. Those lines can be used as parents in hybrid breeding or for population improvement approaches to develop diverse genotypes in the segregating generations. With the objective to broaden the genetic base of the released varieties and to increase the fibre yield, as a first step the present investigation was undertaken to investigate the nature and 
magnitude of genetic diversity in 81 tossa jute Corchorus olitorius L.genotypes.

\section{MATERIALS AND METHODS}

We have selected 100 genotypes from the germplasm which includes exotic, indigenous and the germplasm collected through IJO (International Jute Organization) and mutants. But out of 100 only 81 genotypes were germinated and were used for phenotypic evaluation. The genotypes were randomised in three replications. Data was collected on five characters i.e., Plant height $(\mathrm{cm})$, Basal diameter $(\mathrm{cm})$, Green weight $(\mathrm{g})$, Fibre yield (g) and stick weight (g). Data on different quantitative characters were taken on five randomly selected plants. Green weight was taken after harvesting; leaves will be shredded from the stem and then weighed and recorded as green weight. For the character stick weight, after retting and fibre extraction left over jute sticks were sun dried and weighed. Diversity analysis was carried out by using Mahalanobis $\mathrm{D}^{2}$ statistics (Rao, 1952). The genotypes were grouped based on Euclidean squared distances and ward's method as described by Singh and Choudhary (1979). D ${ }^{2}$ statistics, cluster mean analysis and Principal component analysis was carried out by using Windostat statistical package (WINDOSTAT ver. 9.1).

\section{RESULTS AND DISCUSSION}

Cluster mean analysis: Analysis of variance showed significant $(P<0.01)$ differences among the genotypes for all the characters studied, which indicated the presence of variation among the tossa jute genotypes stud- ied. Mean values of traits for each cluster are presented in table 1. For the character plant height, cluster VI having high mean value $(350.31 \mathrm{~cm})$ followed by cluster VII $(344.50 \mathrm{~cm})$ and Cluster X $(344.27 \mathrm{~cm})$. For the character basal diameter cluster III having low mean value $(1.55 \mathrm{~cm})$ followed by cluster $I(1.59 \mathrm{~cm})$ and cluster IV $(1.60 \mathrm{~cm})$. This character is more important as it is closely associated with fibre fineness. Similarly, for green weight cluster X (313.63g) followed by cluster IX (271.85g) and cluster VIII (264.72g). For fibre yield cluster IX (19.91g) followed by cluster VII $(18.94 \mathrm{~g})$ and cluster $\mathrm{X}(15.86 \mathrm{~g})$ and for stick weight cluster X (57.85g) followed by cluster IX (46.54g) and VIII (46.23g). Results revealed that stick weight $(65.52 \%)$ contributes maximum to the total diversity, followed by green weight $(13.64 \%)$, fibre yield $(10.10 \%)$, plant height $(7.40 \%)$ and basal diameter (3.34\%), similar kind of results were reported by Roy et al., (2011), Ghosh et al., (2014) while working on jute crop.

Cluster analysis: Intra and inter cluster distances among ten tossa jute clusters were presented in table 2 . The highest inter cluster distance was observed between cluster II and cluster X (186.80) followed by cluster IV and cluster X (161.26), cluster II and cluster IX (129.00) and cluster III and cluster X (125.56) indicating the presence of high genetic divergence between these clusters, similar kind of results in tossa jute was reported by Akter et al., (2010) and Roy et al., (2011) while estimating genetic diversity. Selecting tossa jute genotypes from high inter cluster distances with high mean values for fibre yielding characters will help in

Table 1. Cluster means for fibre yield and yield attributing characters in tossa jute.

\begin{tabular}{llllll}
\hline Cluster no. & Plant height $\mathbf{( c m )}$ & Basal diameter $\mathbf{( c m )}$ & Green weight $\mathbf{( g )}$ & Stick weight $(\mathbf{g})$ & Fibre yield (g) \\
\hline I & 323.55 & 1.59 & 193.15 & 32.20 & 12.55 \\
II & 290.29 & 1.80 & 142.53 & 22.08 & 8.84 \\
III & 305.31 & 1.55 & 176.91 & 26.84 & 10.98 \\
IV & 310.08 & 1.60 & 165.82 & 22.58 & 14.26 \\
V & 326.44 & 1.68 & 239.95 & 38.50 & 13.65 \\
VI & 350.31 & 1.67 & 225.28 & 33.00 & 14.40 \\
VII & 344.50 & 1.74 & 255.91 & 35.17 & 18.94 \\
VIII & 335.02 & 1.88 & 264.72 & 46.23 & 14.58 \\
IX & 343.15 & 1.96 & 271.85 & 46.54 & 19.91 \\
X & 344.27 & 1.67 & 313.63 & 57.85 & 15.86 \\
Mean & 324.96 & 3.34 & 13.64 & 34.73 & 13.59 \\
Contribution of char- & 7.40 & & & 65.52 & 10.10 \\
acters to diversity (\%) & & & &
\end{tabular}

Table 2. Average inter and intra cluster distances $\left(\mathrm{D}^{2}\right.$ values) for ten clusters in eighty one tossa jute genotypes.

\begin{tabular}{|c|c|c|c|c|c|c|c|c|c|c|}
\hline Cluster no. & I & II & III & IV & $\mathbf{V}$ & VI & VII & VIII & IX & $\mathbf{X}$ \\
\hline I & 6.49 & 35.97 & 10.26 & 18.34 & 14.47 & 12.18 & 27.13 & 34.00 & 47.07 & 91.92 \\
\hline II & & 20.34 & 22.93 & 29.12 & 65.07 & 55.14 & 90.27 & 102.03 & 129.00 & 186.80 \\
\hline III & & & 7.28 & 13.44 & 26.49 & 20.67 & 41.82 & 54.74 & 72.94 & 125.56 \\
\hline IV & & & & 6.56 & 41.78 & 23.63 & 37.72 & 77.63 & 81.52 & 161.26 \\
\hline V & & & & & 7.22 & 16.33 & 21.40 & 13.64 & 25.03 & 49.96 \\
\hline VI & & & & & & 7.51 & 15.44 & 34.97 & 40.74 & 90.80 \\
\hline VII & & & & & & & 6.64 & 33.73 & 22.96 & 79.02 \\
\hline VIII & & & & & & & & 7.83 & 16.79 & 21.28 \\
\hline IX & & & & & & & & & 8.23 & 30.86 \\
\hline X & & & & & & & & & & 3.18 \\
\hline
\end{tabular}


Table 3. Principal component analysis for fibre yield and yield attributing characters in tossa jute.

\begin{tabular}{llll}
\hline Characters & Vector 1 & Vector 2 & Vector 3 \\
\hline Plant height (cm) & 0.465 & 0.381 & 0.052 \\
Basal Diameter (cm) & 0.296 & -0.674 & 0.665 \\
Green weight (g) & 0.543 & -0.076 & -0.349 \\
Stick Weight (g) & 0.502 & -0.299 & -0.44 \\
Fibre yield (g) & 0.386 & 0.553 & 0.49 \\
Eigene Value (Root) & 2.617 & 1.084 & 0.615 \\
\% Var. Exp. & 52.34 & 21.67 & 12.29 \\
Cum. Var. Exp. & 52.34 & 74.01 & 86.30 \\
\hline
\end{tabular}

developing high heterotic hybrids and also useful in selecting better recombinants in the segregating generations for higher fibre yield.

In the present study highest intra cluster distances was recorded in cluster II (20.34), indicating high variation among the genotypes in the cluster and lowest in cluster X (3.17) indicating less variation among the genotypes in this cluster. The average inter cluster distances were higher than the average intra cluster distances, which indicates the presence of wide genetic diversity among the genotypes of different clusters than those of same cluster.

Principal component analysis: The first two principal components whose eigene values are greater than one, accounting for $74 \%$ of the total variation among the tossa jute genotypes assessed for five characters. First principal component explained variance about $52.34 \%$, second $21.67 \%$ and third $12.29 \%$ of the total variance (table 3), similar kind of results were reported by Denton and Nwangburuka (2012) and Ghosh et al., (2014) in jute crop.

Characters are having high vector values closer to one within the given principal component and influence the cluster more than the variables having low values closer to zero (Chahal and Goshal, 2002). In the first principal component green weight, stick weight and plant height recorded high vector values, similar kind of results were reported by Akter et al., (2010), Denton and Nwangburuka (2012). In the second principal component fibre weight and plant height recorded positive values and basal diameter, stick weight and green weight recorded negative values. Further in the third principal component, high positive values were recorded by basal diameter, fibre weight and negative values by stick weight and green weight.

\section{Conclusion}

The results of the present study indicated the presence of high genetic variability among the tested jute genotypes. Based on diversity analysis, parents from distant clusters with high mean values for fibre yield and yield attributing traits can be utilized for crossing programme for developing economically useful recombinants.

\section{ACKNOWLEDGEMENTS}

Authors are thankful to Director ICAR-CRIJAF, Barrackpore for providing resources and facilities for con- ducting the experiment.

\section{REFERENCES}

Abdurakhmonov, I. and Abdukarimov, A. (2008). Application of association mapping to understanding the genetic diversity of plant germplasm resources. International Journal of Plant Genomics, : 1-18.

Akter, N., Islam, M.M., Yahiya, A.S.M. and Newaz, M.A. (2010). Genetic divergence for fibre and seed characters in tossa jute (Corchorus olitorius L.). Journal of Experimental Bioscience, 1 (1): 7-12.

Benor, S., Demissew, S., Hammer, K. and Blattner, F.R. (2012). Genetic diversity and relationships in Corchorus olitorius (Malvaceae s. 1.) inferred from molecular and morphological data. Genet. Resour. Crop Evol., 59:1125-1146.

Chahal, G.S. and Goshal, S.S. (2002). Principals and Procedures of Plant Breeding: Biotechnology and Conventional Approaches. Narosa Publishing House, New Delhi.

Denton, O.A. and Nwangburuka, C.C. (2012). Morphological Diversity among Corchorus olitorius Accessions Based on Single Linkage Cluster Analysis and Principal Component Analysis. Jordan Journal of Biological Science,s 5(3): 191-196.

Edmonds, J.M. (1990). Herbaroum survey of African Corchorus L. species. International Board for Plant Genetic Resources, Rome.

Ghosh, R.K., Wongkaew, A., Sreewongchai, T., Nakasathien, S. and Phumichai, C. (2014). Assessment of Genetic Diversity and Population Structure in Jute (Corchorus spp.) Using Simple Sequence Repeat (SSR) and Amplified Fragment Length Polymorphism (AFLP) Markers. Kasetsart J. (Nat. Sci.), 48: 83-94.

Kar, C.S., Kundu, A., Sarkar D., Sinha, M.K., and Mahaptra, B.S. (2009). Genetic diversity in jute (Corchorus spp.) and its utilization: a review. Indian J. Agric. Sci., 79 (8): 575-86.

Kundu, A., Topdar, N., Sarkar, D., Sinha, M.K., Ghosh, A., Banerjee, S., Das, M., Balyan, H.S., Mahapatra, B.S. and Gupta, P.K. (2013). Origins of white (Corchorus capsularis L.) and dark (C. olitorius L.) jute: a reevaluation based on nuclear and chloroplast microsatellites. $J$. Plant Biochem. Biotechnol., 22: 372-381.

Mahapatra, A.K. and Saha, A. (2008) Genetic resources of jute and allied fibre crops., Jute and allied fibre updates, Central Research Institute for Jute and Allied Fibres, Kolkata, pp.18-37.

Rao, C.R. (1952). Advanced statistical methods in biometrical Research. John Wiley and sons, New York. pp 357-369.

Rowell, R.M. and Stout, H.P. (2007). Jute and kenaf. Handbook of fibre chemistry, CRC Press, Boca Raton, pp 405-452.

Roy, S.K., Das, B., Kale, V.A. and Haque, S. (2011). Genetic divergence study for yield and quality traits in tossa jute (Corchorus olitorius). Journal of Crop and Weed, 7(1): 130-132.

Singh, R.K. and Choudhary, B.D. (1979). Biometrical methods in quantitative genetic analysis. Kalyani Publishers, New Delhi, India. Pp 211-215.

Sinha, M.K., Kar, C.S., Ramasubramanian, T., Kundu, A. and Mahapatra, B.S. (2011). Corchorus. Wild crop relatives: genomic and breeding resources, industrial crops.Springer, Berlin, pp 29-61.

State wise production of raw jute, Retrieved on12-02-2015 www.jutecomm.gov.in/ production.htm 